\title{
Distinct 17- and 33-Day Tropical Instability Waves in Subsurface Observations*
}

\author{
JOHN M. LYMAN \\ Joint Institute for Marine and Atmospheric Research, University of Hawaii at Manoa, Honolulu, Hawaii, and NOAA/Pacific Marine \\ Environmental Laboratory, Seattle, Washington \\ Gregory C. Johnson AND William S. KessLeR \\ NOAA/Pacific Marine Environmental Laboratory, Seattle, Washington
}

(Manuscript received 24 January 2006, in final form 30 June 2006)

\begin{abstract}
Tropical instability waves (TIWs) within a half-degree of the equator in the Pacific Ocean have been consistently observed in meridional velocity with periods of around 20 days. On the other hand, near $5^{\circ} \mathrm{N}$, TIWs have been observed in sea surface height (SSH), thermocline depth, and velocity to have periods near 30 days. Tropical Atmosphere-Ocean (TAO) Project moored equatorial velocity and temperature time series are used to investigate the spatial and temporal structure of TIWs during 3 years of La Niña conditions from 1998 through 2001 . Along $140^{\circ} \mathrm{W}$, where the TIW temperature and velocity variabilities are at their maxima, these variabilities include two distinct TIWs with periods of 17 and 33 days, rather than one broadbanded process. As predicted by modeling studies, the 17-day TIW variability is shown to occur not only in meridional velocity at the equator, but also in subsurface temperature at $2^{\circ} \mathrm{N}$ and $2^{\circ} \mathrm{S}$, while the 33-day TIW variability is observed primarily in subsurface temperature at $5^{\circ} \mathrm{N}$. These two TIWs, respectively, are shown to have characteristics similar to a Yanai wave/surface-trapped instability and an unstable first meridional mode Rossby wave. One implication of such a description is that the velocity variability on the equator is not directly associated with the dominant 33 -day variability along $5^{\circ} \mathrm{N}$.
\end{abstract}

\section{Introduction}

In the Pacific Ocean, tropical instability waves (TIWs) have classically been characterized by meanders in the sea surface temperature (SST) front just north of the equator. These meanders, as observed in early satellite SST images, were estimated to have 25day periods and 1000-km wavelengths (Legeckis 1977). The description of TIWs has since been broadened to include additional analyses of sea surface height ( $\mathrm{SSH}$ : Miller et al. 1985; Malardé et al. 1987; Musman 1989; Périgaud 1990), velocity (Halpern et al. 1988; Bryden and Brady 1989; Qiao and Weisberg 1995; McPhaden

\footnotetext{
* Pacific Marine Environmental Laboratory Contribution Number 2701 and Joint Institute for Marine and Atmospheric Research Contribution Number 06-362.
}

Corresponding author address: John M. Lyman, Pacific Marine Environmental Laboratory, NOAA/R/PMEL, 7600 Sand Point Way, Seattle, WA 98115.

E-mail: john.lyman@noaa.gov

DOI: $10.1175 / J P O 3023.1$

(C) 2007 American Meteorological Society
1996; Kennan and Flament 2000), wind stress (Xie et al. 1998; Chelton et al. 2001; Hashizume et al. 2001), ocean color (Strutton et al. 2001), subsurface temperature (McPhaden 1996; Flament et al. 1996; Kennan and Flament 2000), and SST (Legeckis et al. 1983; Legeckis 1986; Pullen et al. 1987; Contreras 2002). These investigations have expanded the definition of TIWs to include variability occurring north and south of the equator with a large range of periods (15-40 days) and wavelengths $(700-1600 \mathrm{~km})$.

Observations of TIWs in the equatorial Pacific from in situ measurements of subsurface temperature and velocity along with satellite measurements of $\mathrm{SSH}$ have fallen into two categories that vary geographically and are dependent on the observed field. The first has periods around 15-23 days, has been observed within a degree of the equator, and is most prominent in meridional velocity (Halpern et al. 1988; Bryden and Brady 1989; Qiao and Weisberg 1995; McPhaden 1996). The second has periods around 28-35 days and has been observed in SSH, thermocline depth, and velocity centered about $5^{\circ} \mathrm{N}$ (Miller et al. 1985; Malardé et al. 


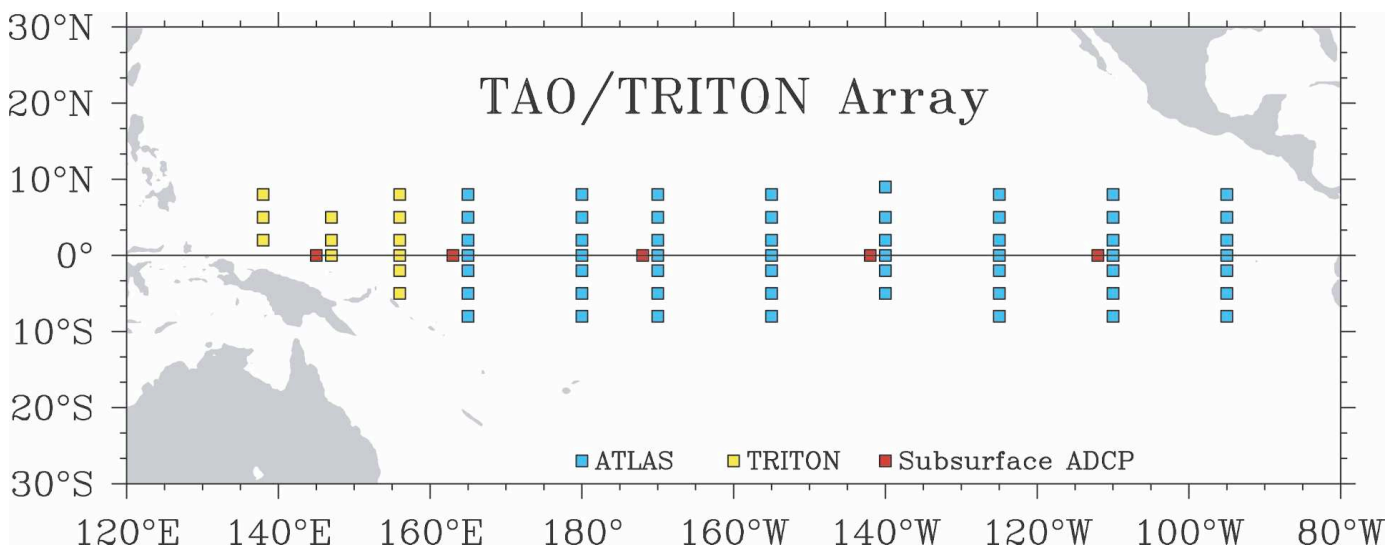

FIG. 1. TAO/TRITON Array mooring locations.

1987; Musman 1989; Périgaud 1990; McPhaden 1996; Flament et al. 1996; Kennan and Flament 2000). Throughout this paper, variability with periods between 15 and 23 days is referred to as 17-day variability. Likewise, variability with periods between 28 and 35 days is referred to as 33-day variability.
Nonlinear numerical models and linear stability analyses of the equatorial Pacific reproduce aspects of either the 33-day variability (Philander 1978; Cox 1980; Lyman et al. 2005) or both the 33-day and the 17-day variability (McCreary and Yu 1992; Proehl 1996; Donohue and Wimbush 1998; Masina et al. 1999a; Seidel and
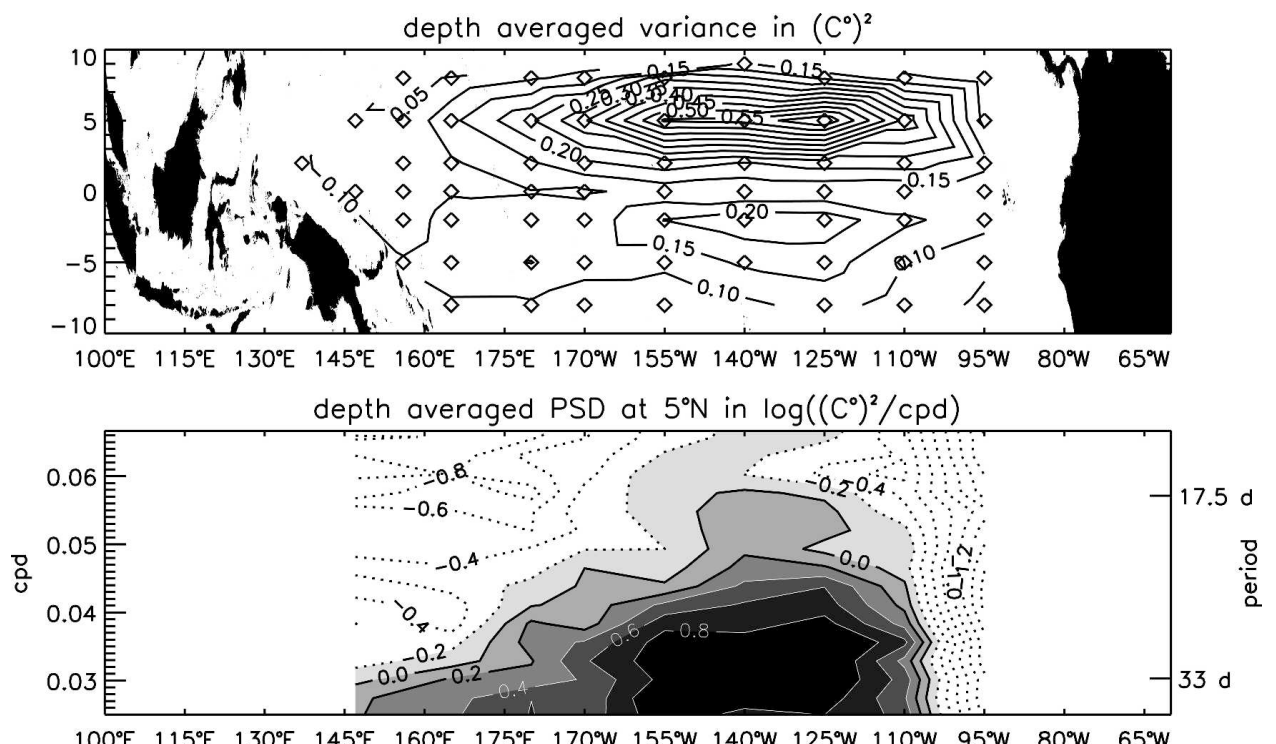

$100^{\circ} \mathrm{E} 115^{\circ} \mathrm{E} 130^{\circ} \mathrm{E} 145^{\circ} \mathrm{E} 160^{\circ} \mathrm{E} 175^{\circ} \mathrm{E} 170^{\circ} \mathrm{W} 155^{\circ} \mathrm{W} 140^{\circ} \mathrm{W} 125^{\circ} \mathrm{W} 110^{\circ} \mathrm{W} \quad 95^{\circ} \mathrm{W} \quad 80^{\circ} \mathrm{W} \quad 65^{\circ} \mathrm{W}$

depth averaged PSD at $2^{\circ} \mathrm{S}$ in $\log \left(\left(\mathrm{C}^{\circ}\right)^{2} / \mathrm{cpd}\right)$

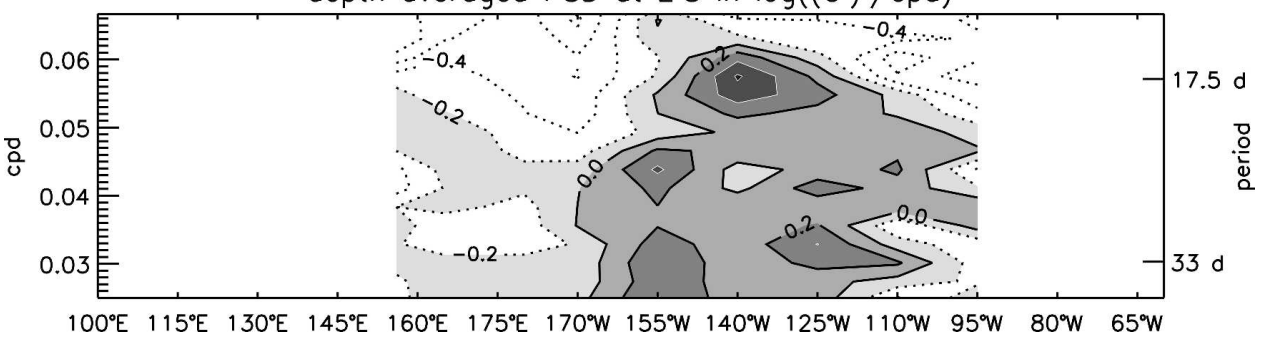

FIG. 2. Depth-averaged (top) variance of filtered temperature from the TAO mooring array and depth-averaged PSD at (middle) $5^{\circ} \mathrm{N}$ and (bottom) $2^{\circ} \mathrm{S}$. Variance and spectra were computed over the same 3-yr period beginning in May 1998. Diamonds in the top panel show mooring locations. 

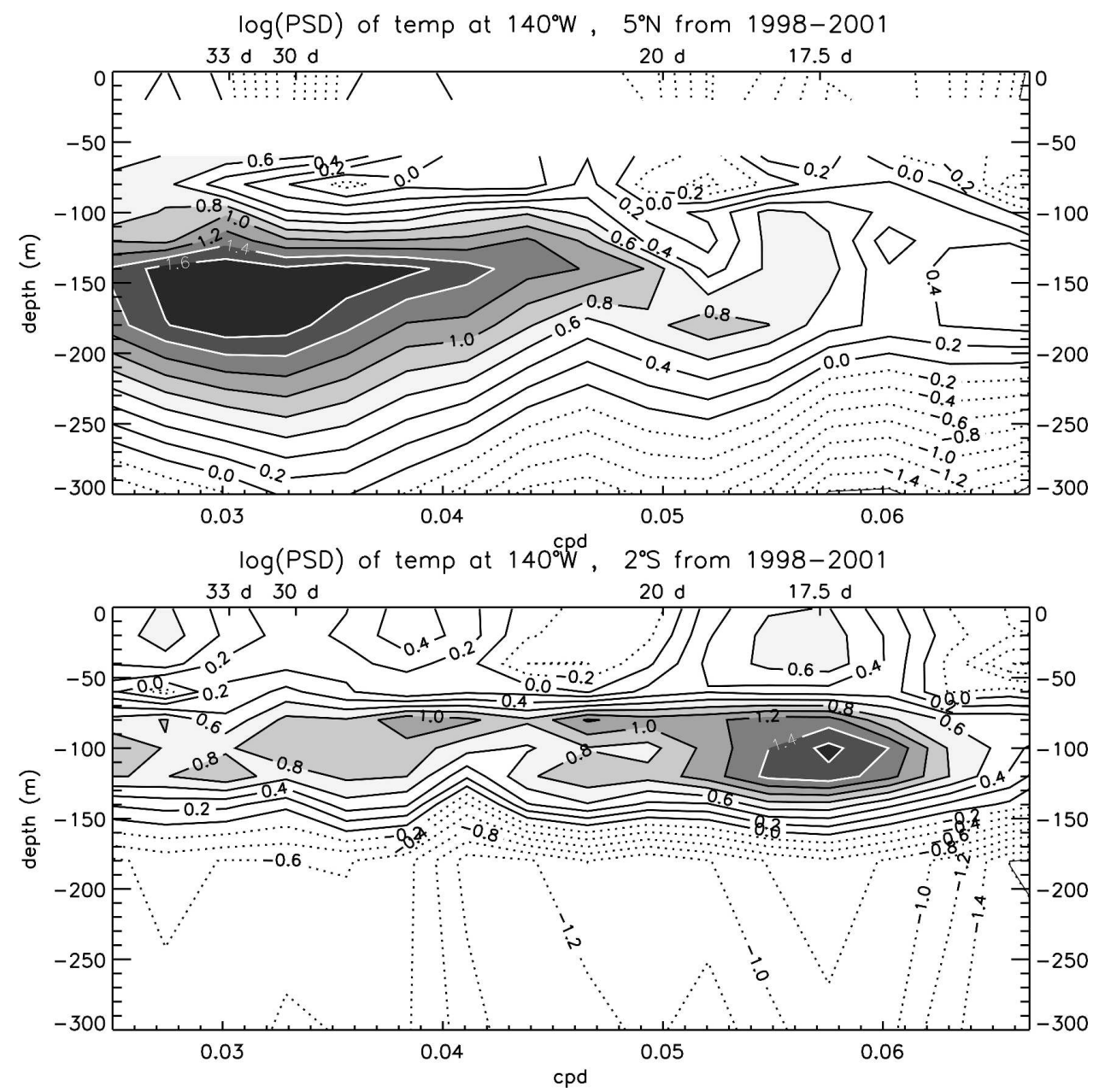

FIG. 3. PSD of filtered temperature vs depth from the TAO mooring array at (top) $5^{\circ} \mathrm{N}, 140^{\circ} \mathrm{W}$ and (bottom) $2^{\circ} \mathrm{S}, 140^{\circ} \mathrm{W}$.

Giese 1999), and sometimes contain other instabilities that fall outside of these two categories. The structure of the 17-day variability in these models, although not always shown, has an off-equator signal in SSH and subsurface temperature separate from the 33-day variability. We are not aware of direct observational evidence for these 17-day signatures in past analyses of either SSH or subsurface temperature.

The lack of observational evidence of 17-day TIW variability off the equator makes it difficult to interpret how or if TIW variability in velocity on the equator is related to TIW variability off the equator. Experimental studies of energetics have long shown that TIW variability on and off the equator are different. Luther and Johnson (1990) found three regions of TIW energy transfer from shipboard acoustic Doppler current profiler (ADCP) sampling. The first region is between the Equatorial Undercurrent (EUC) and the north branch of the South Equatorial Current (SECN), where mean kinetic energy is converted to eddy kinetic energy. The second region is at the Equatorial Front (EF), where mean potential energy is converted to eddy potential energy. The last region is in the thermocline near the North Equatorial Countercurrent (NECC), where mean kinetic energy is converted to eddy potential energy. Some or all of these regions of instability have also been observed in drifter data (Hansen and Paul 1984; Baturin and Niiler 1997), in the analysis of moored current measurements (Halpern et al. 1988; Bryden and Brady 1989; Qiao and Weisberg 1995, 1998), and from a combined analysis of moorings, shipboard ADCPs, and drifters (Kennan 1997; Kennan and Flament 2000).

In a linear framework, an instability is most readily identified by its period, growth rate, wavelength, or cross-equatorial structure. A single instability can have different types of energy transfer mechanisms that vary with latitude. Published analyses identify location and 

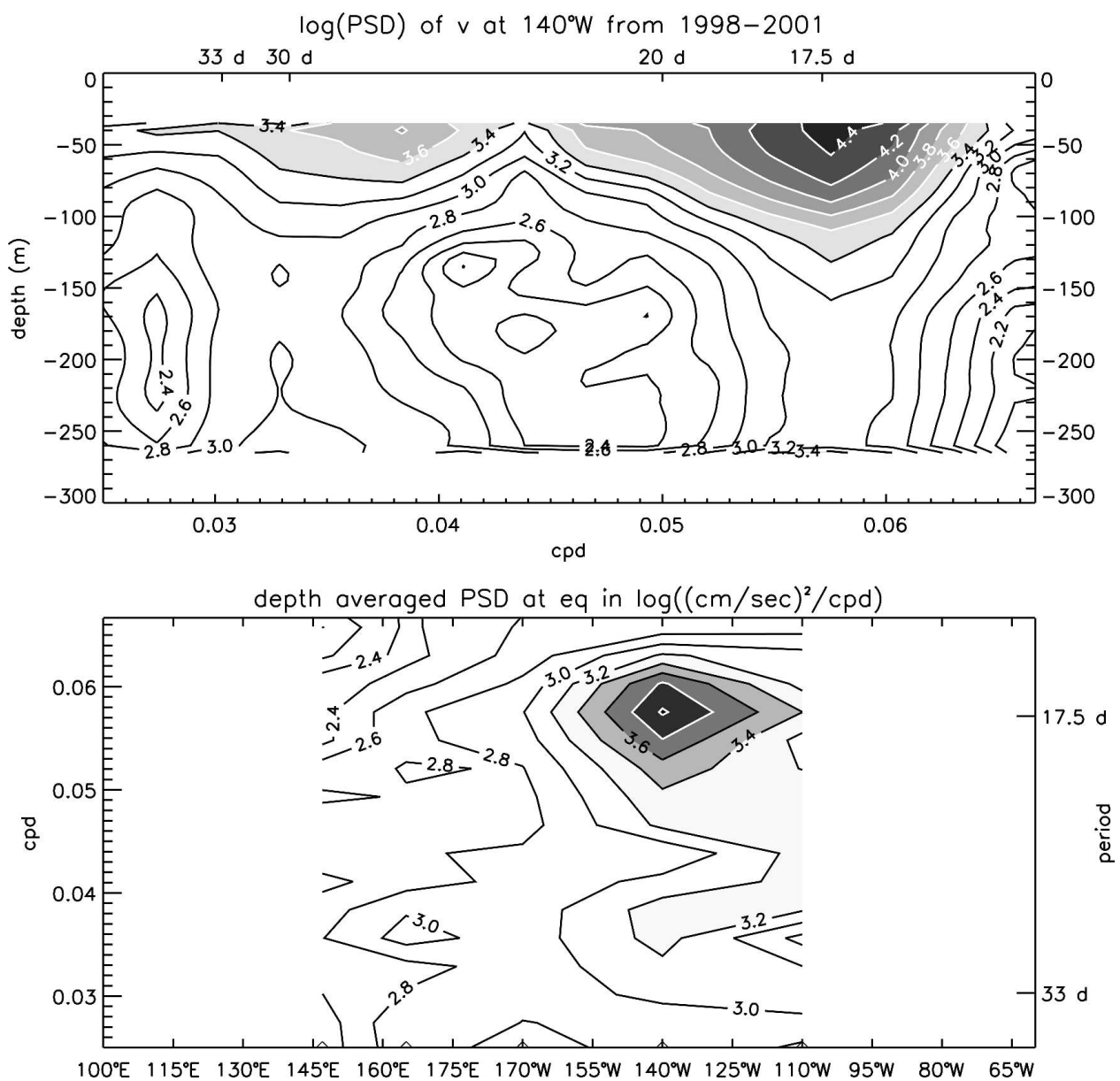

FIG. 4. PSD of filtered meridional velocity from the TAO mooring array at (top) $0^{\circ}, 140^{\circ} \mathrm{W}$. (bottom) Depth-averaged PSD of filtered velocity at the equator from the TAO mooring array. Diamonds in the bottom panel show mooring locations.

type of energy transfer but either cannot resolve the period (Hansen and Paul 1984; Baturin and Niiler 1997; Luther and Johnson 1990; Kennan 1997; Kennan and Flament 2000) or are confined to within $1^{\circ}$ of the equator and cannot resolve the latitudinal structure of the TIW variability (Halpern et al. 1988; Bryden and Brady 1989; Qiao and Weisberg 1995; Kennan 1997; Qiao and Weisberg 1998; Kennan and Flament 2000), making it difficult to identify the relationship between TIW variability in velocity on the equator and TIW variability in temperature off the equator.

McPhaden (1996) investigated the structure of TIWs during 1988-89 using temperature data from six moorings that were part of the Tropical Ocean and Global Atmosphere (TOGA) Tropical Atmosphere-Ocean (TAO)/NECC array. Moorings along $140^{\circ} \mathrm{W}$ between $2^{\circ} \mathrm{S}$ and $9^{\circ} \mathrm{N}$ allowed for the examination of the period and cross-equatorial structure of the TIWs. Because of the short time series and gaps in the data, the original analysis placed all of the TIW variability into one 1550-day bin, and described TIWs as a broadbanded process. Differences in periods across the equator apparent in the power spectra density were attributed to a "red shift" in the temperature spectra due to advection.

The present analysis uses temperature and velocity data from the TAO mooring array to examine TIW variability from $8^{\circ} \mathrm{S}$ to $9^{\circ} \mathrm{N}, 146^{\circ} \mathrm{E}$ to $95^{\circ} \mathrm{W}$ during a 3 -yr period of La Niña conditions beginning in May 1998. We apply empirical orthogonal function (EOF) gaphandling techniques from Davis (1976) to complex empirical orthogonal functions (CEOFs). This method allowed for excellent frequency resolution. The TIW temperature variability is dominated by the 33-day signal, which extends along $5^{\circ} \mathrm{N}$ from $180^{\circ}$ to $110^{\circ} \mathrm{W}$. This analysis focuses on $140^{\circ} \mathrm{W}$, the longitude with the largest TIW variability both north and south of the equator in the TAO dataset.

The most notable difference between McPhaden 
a) Meridional Velocity $(\mathrm{cm} / \mathrm{sec})$ at $140^{\circ} \mathrm{W}, 0^{\circ} \mathrm{N} 1999-2000$

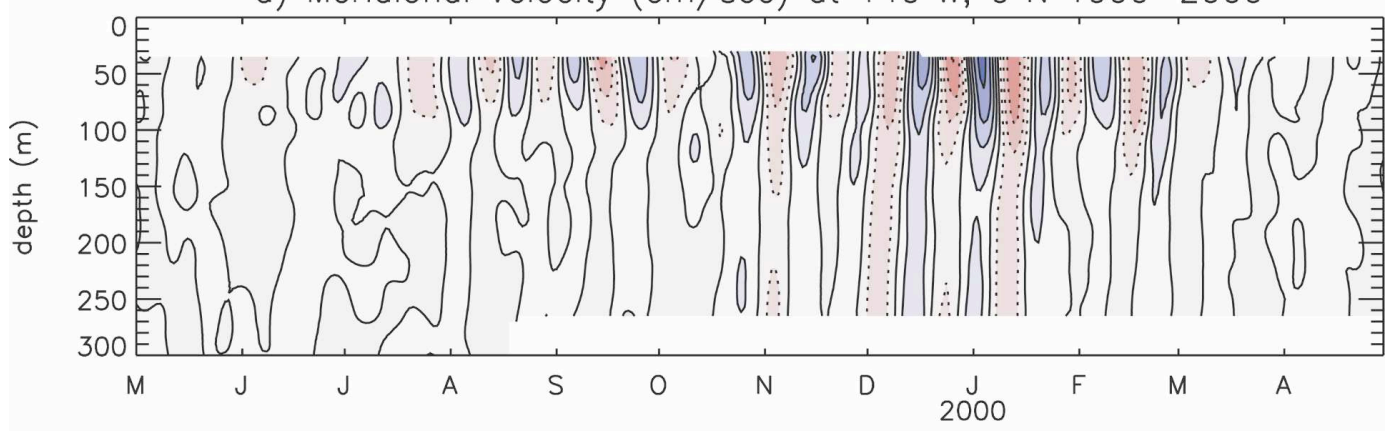

b) Zonal Velocity $(\mathrm{cm} / \mathrm{sec})$ at $140^{\circ} \mathrm{W}, 0^{\circ} \mathrm{N} 1999-2000$

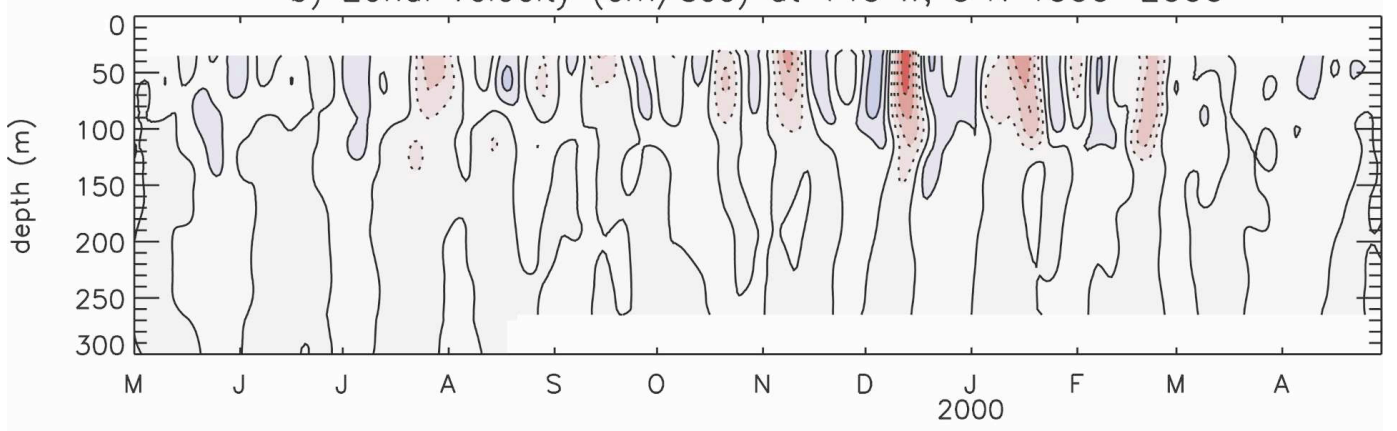

c) Temperature at $140^{\circ} \mathrm{W}, 5^{\circ} \mathrm{N} 1999-2000$

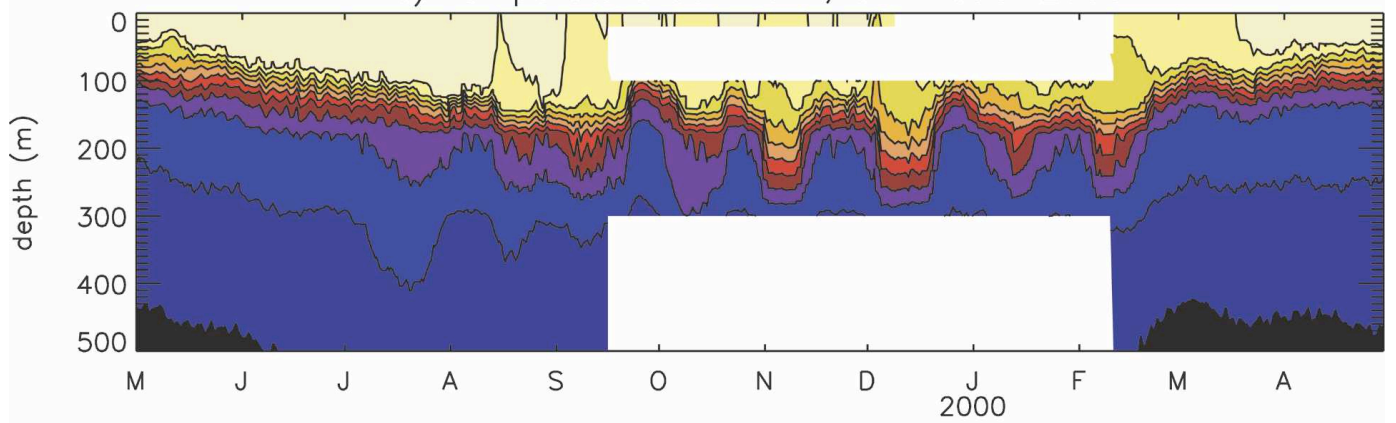

d) Temperature at $140^{\circ} \mathrm{W}, 2^{\circ} \mathrm{S} 1999-2000$

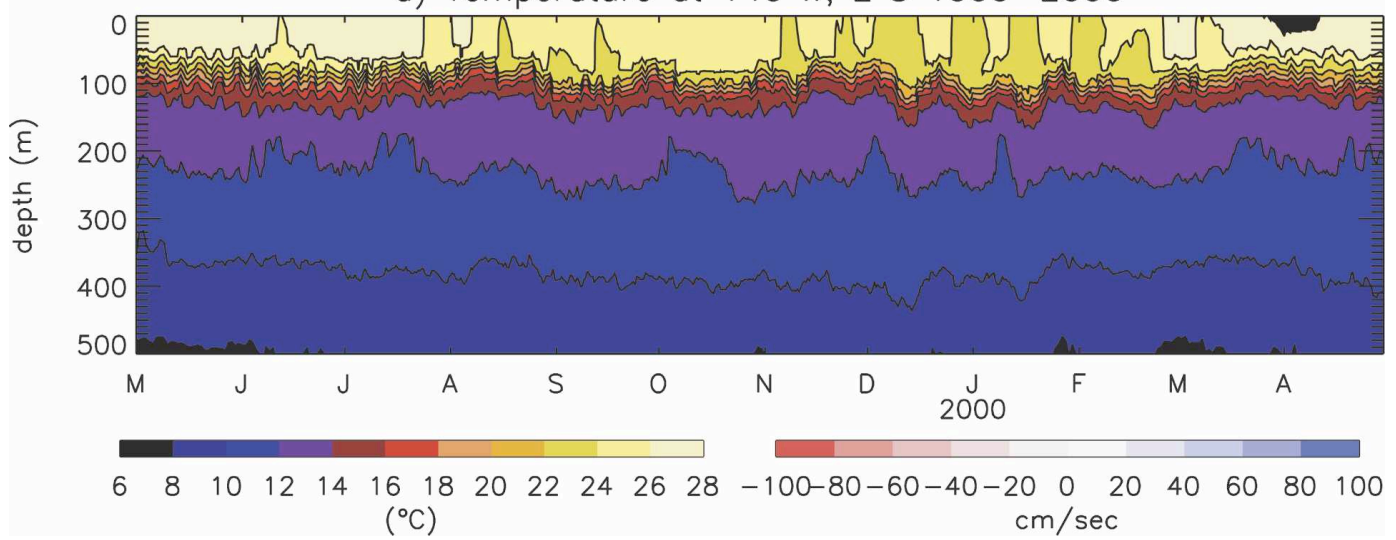

FIG. 5. Time-depth plots of filtered (a) meridional and (b) zonal velocities at $0^{\circ}, 140^{\circ} \mathrm{W}$, and unfiltered temperature at (c) $2^{\circ} \mathrm{S}, 140^{\circ} \mathrm{W}$ and (d) $5^{\circ} \mathrm{N}, 140^{\circ} \mathrm{W}$. 
(1996) and this study is the isolation of the latitudinal structure of the 17-day variability in subsurface temperature that has maxima at $\pm 2^{\circ}$ from the equator, is larger south of the equator, and is correlated with 17day meridional velocity variability on the equator. These results lead us to conclude that equatorial 17-day velocity variability is not directly related to 33 -day temperature variability off the equator. These separate signals represent not one broadbanded processes, but two separate processes with different cross-equatorial structure, period, and presumably different dynamics and energetics. The 17-day variability is shown to share characteristics with a surface-trapped instability/Yanai wave and the 33-day variability with an unstable first meridional mode Rossby wave.

Surface-trapped instabilities have been seen to generate Yanai waves that dissipated TIW energy below the thermocline in nonlinear models of the central Pacific (Cox 1980; McCreary and Yu 1992; Masina et al. 1999a). Eriksen and Richman (1988) found observational evidence of Yanai wave energy below $500 \mathrm{~m}$ in the central Pacific consistent with this process. The structure of the 17-day variability reported here and elsewhere is quite similar to a Yanai wave in a resting ocean (Halpern et al. 1988; Chelton et al. 2000). Yet, there are also asymmetries in the cross-equatorial structure of the 17-day variability that do not match a Yanai wave in a resting ocean (Halpern et al. 1988). In the long wavelength limit it has been shown that the phase speed of a Yanai wave is altered by the presence of a mean current (McPhaden and Knox 1979). However, little is known about the structure and dispersion characteristics of a first baroclinic mode Yanai wave with a 17-day period in the presence of a mean current. Here we show the meridional structure and dispersion characteristics of such a Yanai wave and compare them with observations from the TAO array.

Section 2 describes the TAO mooring data and filtering. Section 3 describes the spatial and spectral structure of TTW variability. Section 4 takes a detailed look at the latitudinal structure of the TIW variability at $140^{\circ} \mathrm{W}$, separating 17 -day and 33-day variability. Section 5 compares the observed structures of the 17-day and 33-day TIWs with an unstable Rossby wave and a Yanai wave in the presence of a mean current, respectively. The results are summarized and discussed in section 6.

\section{Data and analysis techniques}

Here we use temperature and velocity measurements from the TAO array (McPhaden et al. 1998) to investigate TIW variability across the Pacific. We then focus

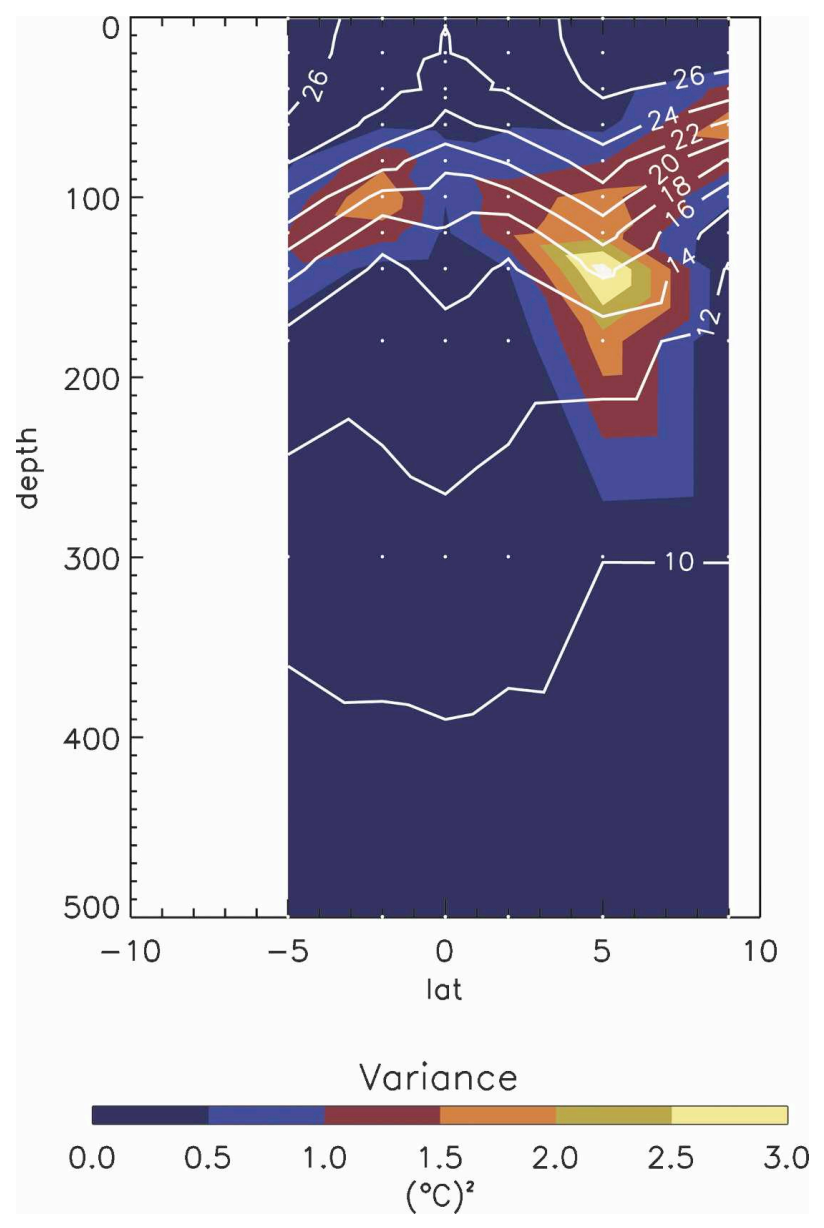

FIG. 6. Variance of bandpass-filtered temperature data at $140^{\circ} \mathrm{W}$ over a 3-yr period beginning in May 1998. Mean isotherms (white lines) from the same time period are overlaid. White dots show the TAO thermistor locations.

along $140^{\circ} \mathrm{W}$ where the TAO array consists of seven moorings: six Autonomous Temperature Line Acquisition System (ATLAS) moorings located at $5^{\circ} \mathrm{S}, 2^{\circ} \mathrm{S}, 0^{\circ}$, $2^{\circ} \mathrm{N}, 5^{\circ} \mathrm{N}$, and $9^{\circ} \mathrm{N}$, and one ADCP mooring on the equator (Fig. 1). Each ATLAS mooring at $140^{\circ} \mathrm{W}$ has 11 thermistors located at depths of 1, 20, 40, 60, 80, 100, $120,140,180,300$, and $500 \mathrm{~m}$. Temperatures are recorded every 10 minutes and then averaged daily. The subsurface upward-looking ADCP nominal bin width and pulse length are set to $8 \mathrm{~m}$. These data are then linearly interpolated to a regular grid with 5-m depth intervals. Velocities are recorded every hour and then averaged daily.

Persistent La Niña conditions were present from May 1998 to May 2001. This period provides a 3-yr record of robust TIW activity in the central Pacific, which can be used to analyze the frequency content of TIWs with greater precision than previously possible (Baturin and Niiler 1997). During this period, there are gaps of a day 

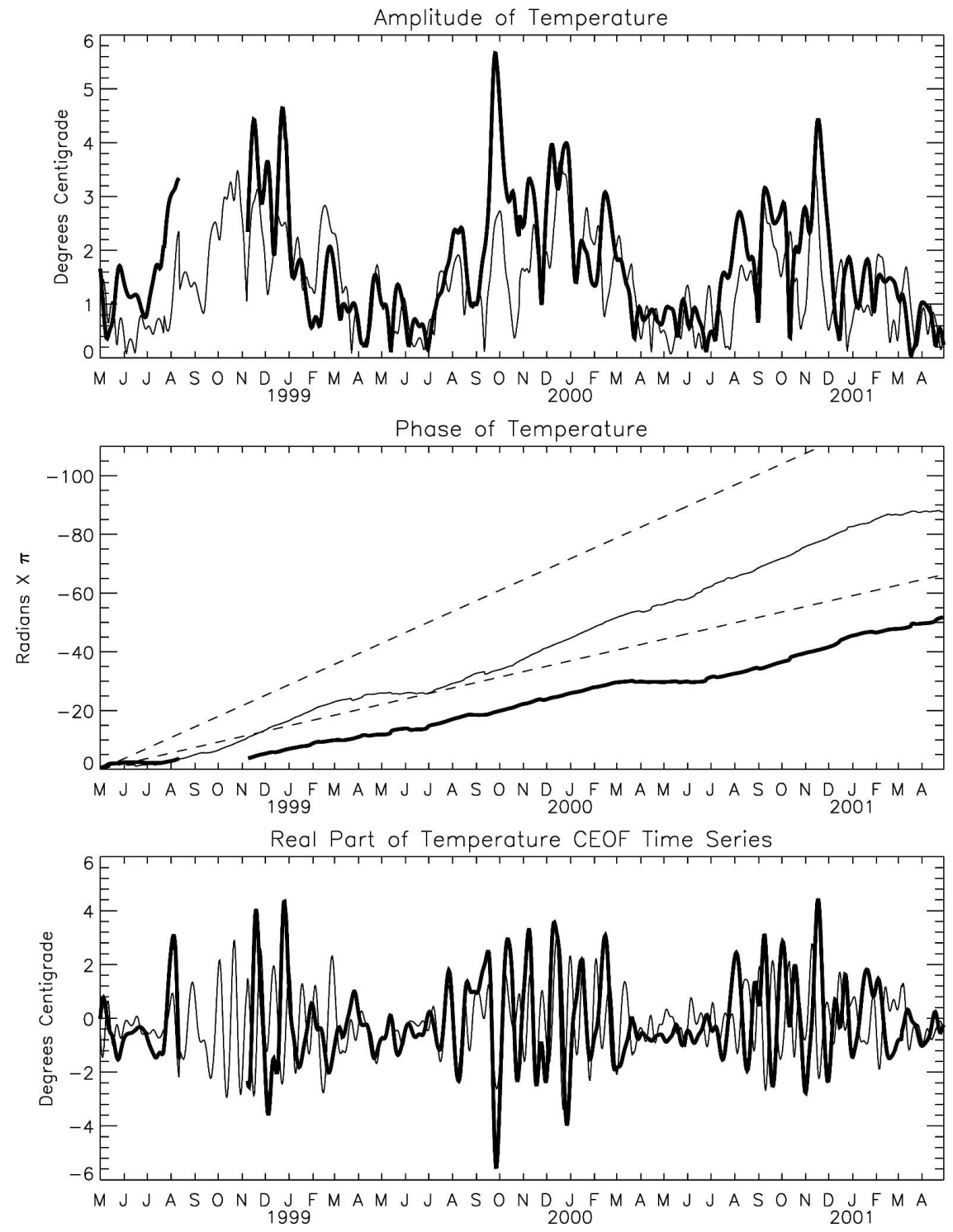

FIG. 7. (top) Amplitude, (middle) phase, and (bottom) real part of the time series for the first two temperature CEOFs along $140^{\circ} \mathrm{W}$. The first mode (thick lines) explains $28 \%$ of the total variance while the second mode (thin lines) explains 13\%. Amplitude and the real part of the time series are multiplied by their maximum spatial amplitudes. Dashed lines in the middle panel correspond to periods of 17 and 33 days. The missing section of the first-mode CEOF was excluded according to criteria described in section 2.

in the velocity record and gaps of days to months in the temperature records. Gaps from 1 to 4 days, short with respect to the TIW periods, are filled by linear interpolation, while longer gaps in the temperature record are unaltered. TIW variability is then isolated by filtering the resulting time series so that periods between 10 and 60 days are retained. These filtered time series are used throughout this analysis unless otherwise stated.

In section 4 , the coherent variability at $140^{\circ} \mathrm{W}$ in velocity and temperature is described by a Hilbert CEOF analysis. CEOFs separate spatial and temporal variability into orthogonal modes that have both amplitude and phase. Unlike the velocity data, the temperature data have significant gaps, which are handled following Davis (1976), who estimated the EOF time series by minimizing the estimated square error (ESE). Times when the ESE was more than $30 \%$ of the variance were treated as missing in the time series.

The power spectral density (PSD) of the CEOF time series, velocity time series, and temperature time series 
are computed by breaking the time series into 1-yr sections with $50 \%$ overlap and then windowing each section with a Hanning window. The power spectral densities of the resulting sections are then averaged, increasing the degrees of freedom (dof) to around nine (Emery and Thomson 2001). Sections containing missing values were not used in the computation of the PSD, decreasing the dof. For example, in the case of the first CEOF of temperature, the first 1-yr section of the time series was not used because it contains missing values.

\section{TIW variability in TAO}

Once TAO temperature data are filtered and depth averaged; two bands of high variability are evident in depth averages, one located at $5^{\circ} \mathrm{N}$ and another centered at $2^{\circ} \mathrm{S}$ (Fig. 2, top panel). These zonally elongated features extend from $180^{\circ}$ to $110^{\circ} \mathrm{W}$ in the north and from $155^{\circ}$ to $110^{\circ} \mathrm{W}$ in the south. The TAO moorings along $140^{\circ} \mathrm{W}$ cut meridionally through the center of the high variability on both sides of the equator and thus are the focus of our analysis.

The longitudinal structure of the TIW frequency content depends on latitude. We examine $5^{\circ} \mathrm{N}$ and $2^{\circ} \mathrm{S}$ because they go through the center of the two maxima in TIW temperature variability. At $5^{\circ} \mathrm{N}$ the depthaveraged PSD has a dominant period of 33 days at all longitudes and is fairly broad banded (Fig. 2, middle panel). The depth-averaged PSD at $2^{\circ} \mathrm{S}$ has a dominant peak at 17.5 days that spans from $155^{\circ}$ to $110^{\circ} \mathrm{W}$ (Fig. 2 , bottom panel). Unlike the 33 -day variability at $5^{\circ} \mathrm{N}$, the 17 -day variability at $2^{\circ} \mathrm{S}$ only dominates at $140^{\circ} \mathrm{W}$.

Not surprisingly, the PSD of temperature variability at $5^{\circ} \mathrm{N}$ and $2^{\circ} \mathrm{S}$ along $140^{\circ} \mathrm{W}$ plotted as a function of depth shows that the strongest signal is confined to the thermocline (Fig. 3). As with the depth-averaged PSD, the 33 -day variability at $5^{\circ} \mathrm{N}, 140^{\circ} \mathrm{W}$ is more broad banded than the 17 -day variability at $2^{\circ} \mathrm{S}, 140^{\circ} \mathrm{W}$.

TAO velocity measurements in the regions of high TIW variability are limited to moorings on the equator spaced about $30^{\circ}$ apart. Most of the energy in the depth-averaged PSD of meridional velocity variability at the equator (Fig. 4, bottom panel) is found at $140^{\circ} \mathrm{W}$ with a period of about 17.5 days. As in the case of the temperature variability at $2^{\circ} \mathrm{S}$, the 17 -day variability in velocity extends from $170^{\circ}$ to $110^{\circ} \mathrm{W}$, but only clearly dominates the spectra at $140^{\circ} \mathrm{W}$. The vertical structure of the meridional velocity at $140^{\circ} \mathrm{W}$ (Fig. 4, top panel) is surface trapped with a clear maximum occurring at 17.5 days. The vertical structure of zonal velocity (not shown) is similar to that of meridional velocity but has about one-quarter the magnitude.

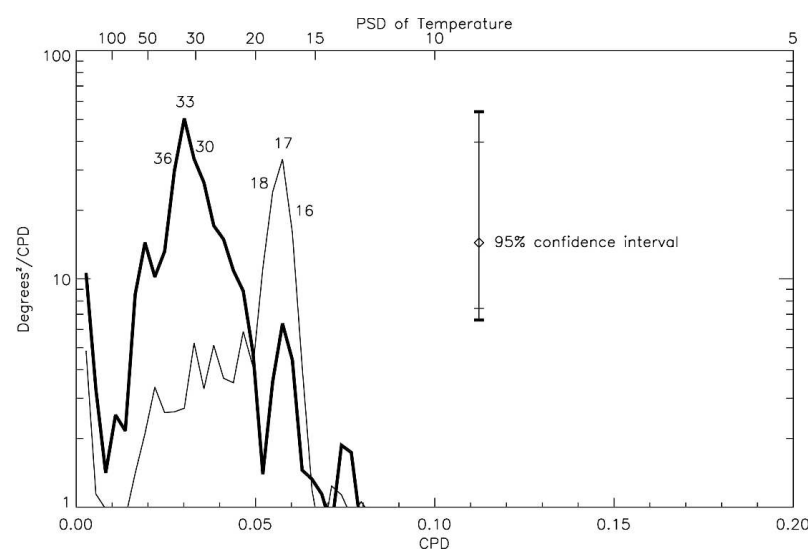

FIG. 8. Power spectral densities of the first (thick line) and second (thin line) temperature CEOFs from Fig. 7, computed according to section 2. Period (days) is plotted on the top $x$ axis and noted on the curve for peaks. The larger error bars are for the first CEOF since the first year of that CEOF has a significant gap.

The period of the spectral peak in meridional velocity over the 3-yr time span from 1998 to 2001 is slightly different than that previously reported by Qiao and Weisberg (1995) during the Tropical Instability Wave Experiment (TIWE) time period from May 1990 to June 1991. The TIWE time span had a clear spectral peak at 21 days (500 h; Qiao and Weisberg 1995), while the 1998-2001 time period studied here has a peak near 17 days. Both 17- and 21-day periods are in the range for 17-day TIWs produced in models (McCreary and Yu 1992; Proehl 1996; Donohue and Wimbush 1998; Masina et al. 1999a; Seidel and Giese 1999). The variation in period is likely due to the changing background conditions that generate TIWs (Johnson and Proehl 2004).

The $15^{\circ}$ and $30^{\circ}$ spacing of the temperature and velocity moorings make it impossible to resolve the 700 $1600-\mathrm{km}$ wavelengths of the TIW signals. However, it is possible to obtain rough estimates of the wavelengths from the lagged correlation of the variability at $140^{\circ} \mathrm{W}$ with variability at other longitudes. Using the temperature time series at the depth of maximum 33-day variability, correlations between $140^{\circ} \mathrm{W}$ and the other mooring locations along $5^{\circ} \mathrm{N}$ were computed (not shown). Correlations above the $90 \%$ confidence interval were found at $155^{\circ}$ and $125^{\circ} \mathrm{W}$ and are consistent with wavelengths of $1481 \pm 150 \mathrm{~km}$ and $1566 \pm 160 \mathrm{~km}$, respectively. Similarly, the 17.5 -day variability in velocity along the equator is consistent with a wavelength of $1389 \pm 80 \mathrm{~km}$ at $170^{\circ} \mathrm{W}$ and $1423 \pm 80 \mathrm{~km}$ at $110^{\circ} \mathrm{W}$ (not shown). There were no meaningful correlations in temperature along $2^{\circ} \mathrm{S}$.

For the remainder of the paper we will focus on data from moorings along $140^{\circ} \mathrm{W}$. We will show how the 
a) 1 st CEOF \% var, $22 \%$

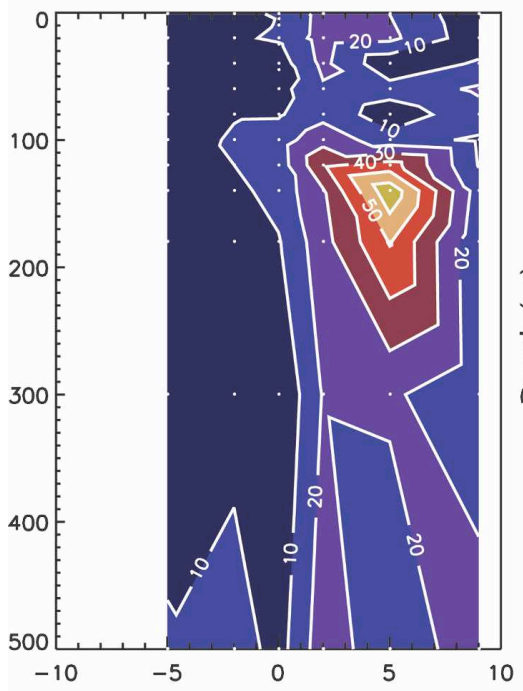

b) 1 st CEOF amplitude $\left({ }^{\circ} \mathrm{C}\right)$

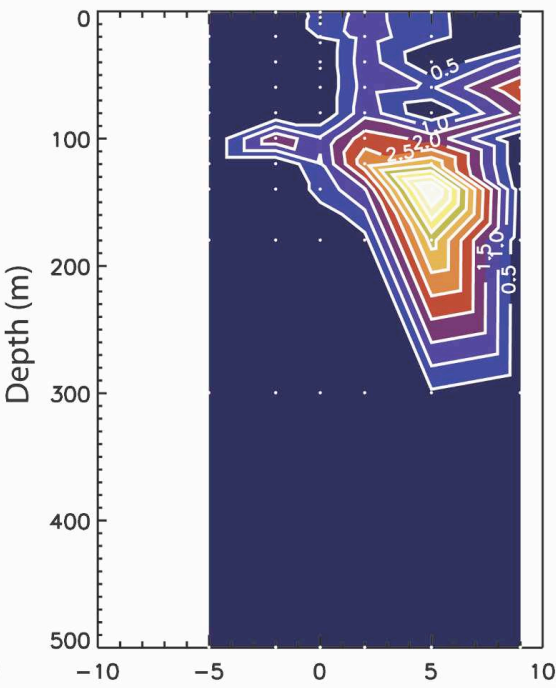

d) Model Rossby amplitude $\left({ }^{\circ} \mathrm{C}\right)$



c) 1 st CEOF Phase in Degrees

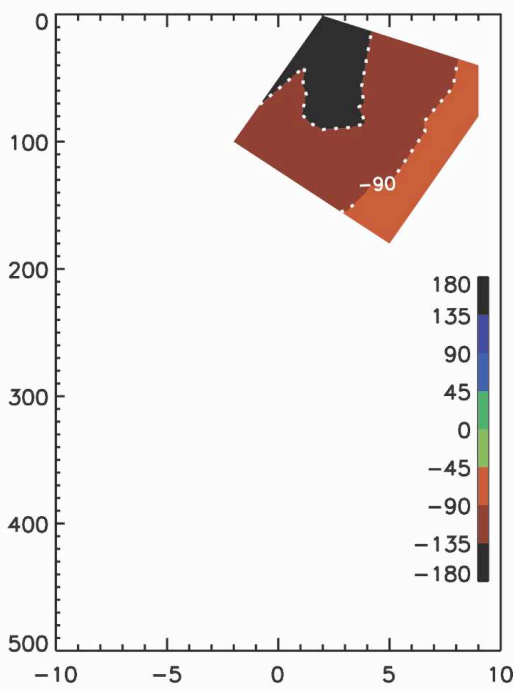

e) Model Rossby Phase in Degrees

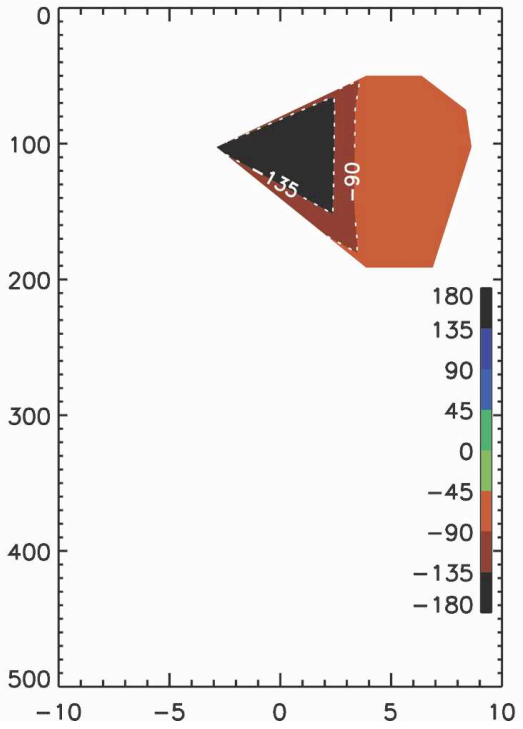

FIG. 9. (a)-(c) Depth-latitude plots for the first CEOF spatial mode of temperature at $140^{\circ} \mathrm{W}$ and (d), (e) the temperature solution for the $n=1, m=1$ unstable Rossby wave from the Lyman et al. (2005) model. Panel (a) shows percent variance explained; (b) shows the CEOF amplitude multiplied by the maxima of the amplitude time series, contoured where at least $10 \%$ of the variance is explained; (c) displays CEOF phase, contoured where the scaled CEOF amplitude exceeds $1^{\circ} \mathrm{C}$ are shown. The model solution has a 31-day period, a 1384-km wavelength, and a 68-day $e$-folding time. The amplitude and phase of temperature from the model are also shown in (d) and (e), respectively. Meridional and zonal velocities are not shown. The amplitude of the model has been scaled to match the CEOF amplitude in (b). To match the phase in both (c) and (e), the phase in (c) has been shifted by $-85^{\circ}$.

17-day variability in velocity at the equator is physically different from the 33-day variability in subsurface temperature at $5^{\circ} \mathrm{N}$ and how the 17-day variability in equatorial velocity is related to the 17-day variability in subsurface temperature at $2^{\circ} \mathrm{S}$.

\section{The structure of TIWs at $140^{\circ} \mathrm{W}$}

The strong TIW oscillations present along $140^{\circ} \mathrm{W}$ are obvious in time-depth plots of unfiltered tempera- ture at $5^{\circ} \mathrm{N}$ and $2^{\circ} \mathrm{S}$ and filtered velocity at the equator (Fig. 5). During the 1999-2000 TIW season, which is representative of the 3-yr record and consistent with previously observed TIW seasonality, TIW variability begins in July and abruptly ends in March. The equatorial TIW velocity signal is dominated by the meridional velocity, which has a range of more than \pm 80 $\mathrm{cm} \mathrm{s}^{-1}$. The thermocline has large undulations of more than $100 \mathrm{~m}$ at $5^{\circ} \mathrm{N}$. The TIW signals are present below 
the thermocline in both meridional velocity on the equator and temperature at $5^{\circ} \mathrm{N}$ and $2^{\circ} \mathrm{S}$. Consistent with the spectral analysis presented in section 3, the periodicities of thermocline depth variation at $2^{\circ} \mathrm{S}$ and velocity on the equator are visibly shorter than those of the thermocline depth variation at $5^{\circ} \mathrm{N}$.

As can be seen from the PSDs in section 3, the velocity on the equator and subsurface temperature at $2^{\circ} \mathrm{S}$ have a dominant period of 17 days, while the subsurface temperature at $5^{\circ} \mathrm{N}$ has a broadbanded peak near 33 days. In the following analysis, the structure of the 33day TIW will be examined first, followed by a description of the 17-day TIW.

\section{a. Thirty-three-day TIW}

As would be expected from the depth-averaged PSD of temperature (Fig. 2), the temperature variance along $140^{\circ} \mathrm{W}$ has maxima at $5^{\circ} \mathrm{N}$ and $2^{\circ} \mathrm{S}$, which occur at the thermocline (Fig. 6). When this variability is broken down into a series of CEOFs, as described in section 2, two modes of variability are evident. The first explains most of the temperature variability at $5^{\circ} \mathrm{N}$ and the second accounts for most of the variability at $2^{\circ} \mathrm{S}$. For now, we will describe the first CEOF, saving the description of the second CEOF of temperature for the next section on 17-day TIW.

The amplitude time series of the first CEOF of temperature has a seasonal modulation, ramping up in July-August and then dissipating in March (Fig. 7), consistent with previous TIW analyses. The linear increase of phase, with occasional pauses occurring only at times when the amplitude time series is small, is characteristic of a periodic signal. These breaks in the phase make it difficult to determine the period of the CEOF from only the phase. Therefore, the period of a CEOF is determined from the PSD of the real part of the CEOF time series (Fig. 7, bottom panel). The first CEOF has a period of $33 \pm 3$ days, where the frequency resolution is based on the 1-yr record length (Fig. 8).

The spatial structure of the first temperature CEOF has maxima at $5^{\circ} \mathrm{N}$ and $2^{\circ} \mathrm{S}$ that are in phase across the equator and much larger north of the equator (Fig. 9, top panels). This mode explains most of the variance in the thermocline at $5^{\circ} \mathrm{N}$ and $22 \%$ of the total variance. The large amplitude at $5^{\circ} \mathrm{N}$ and the 33-day period of this mode are similar to previous analyses of temperature and SSH near $5^{\circ} \mathrm{N}$ (Miller et al. 1985; Malardé et al. 1987; Musman 1989; Périgaud 1990; Flament et al. 1996; Kennan and Flament 2000), and are almost identical to the first-mode CEOF of temperature from McPhaden (1996). The structure of the 33-day subsurface temperature will be compared in detail with previous modeling results (Lyman et al. 2005) in section 5.

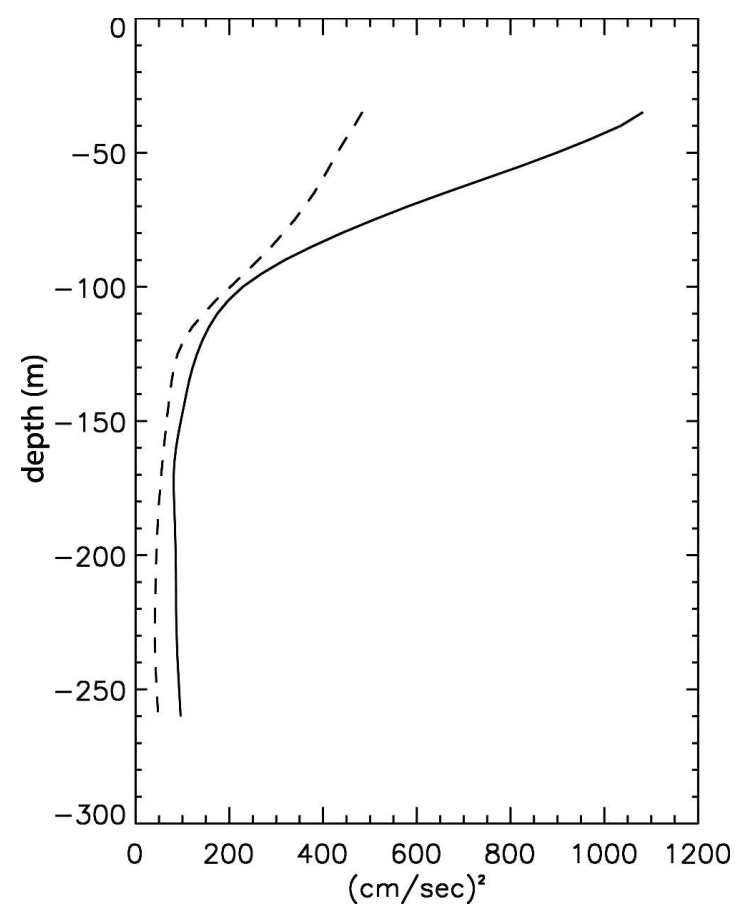

FIG. 10. Variance of bandpass-filtered meridional (solid line) and zonal (dashed line) velocities at $0^{\circ}, 140^{\circ} \mathrm{W}$ over the 3 -yr record beginning in May 1998.

\section{b. Seventeen-day TIW}

As described in section 3, meridional velocity at the equator is surface trapped and dominated by a 17-day period. Like the spectra in Fig. 4, the variance of the filtered velocity is also surface intensified with a meridional variance that is more than twice that of the zonal component (Fig. 10; this ratio is less if expressed as a standard deviation). CEOFs of the meridional and zonal velocity act as a filter, yielding spatial and temporal structure of the 17-day TIW. The first CEOF dominates, explaining $63 \%$ of the filtered velocity variance. Like the first CEOF of temperature, the amplitude time series for the first CEOF of velocity has an annual modulation consistent with the observed TIW season (Fig. 11). Likewise, there are breaks in the phase when the amplitude is small. Hence, the period of the first CEOF of velocity is computed from the PSD of the real part of the CEOF time series (Fig. 11, bottom panel). For the first CEOF the PSD shows a narrowbanded process with a period of about $17 \pm 1$ days, where the frequency resolution is based on the 1-yr record length (Fig. 12). The second CEOF explains $17 \%$ of the variance and cannot be characterized by a distinct period (Fig. 12). Its amplitude time series is inconsistent with the seasonality of TIWs during the 3 -yr record. For these reasons, the rest of the analysis will focus on the first-mode CEOF. 

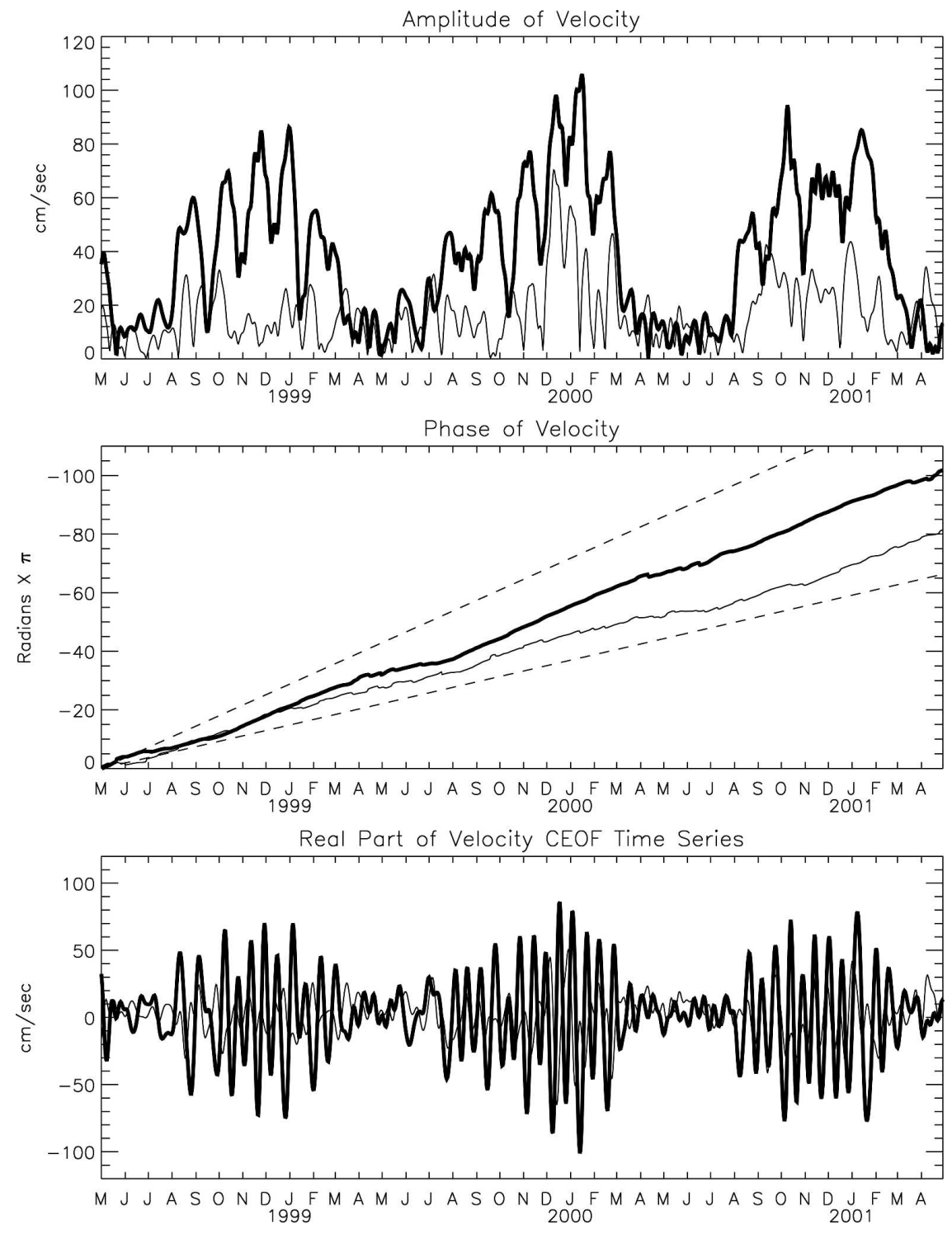

FIG. 11. CEOF analysis following that in Fig. 7 but for the first two combined meridional and zonal velocity CEOFs at $0^{\circ}, 140^{\circ} \mathrm{W}$. The first mode explains $63 \%$ of the total variance while the second mode explains $17 \%$.

The first CEOF is surface trapped and dominated by meridional velocity (Fig. 13). It explains almost all of the filtered meridional velocity variance above $80 \mathrm{~m}$ and $40 \%-50 \%$ of that below the thermocline. However, it only describes a fraction of the filtered zonal velocity variance at the surface and nearly none at depth. The Reynolds stresses associated with this mode (Fig. 13, lower-right panel) are on the same order as those reported by Luther and Johnson (1990) and imply a barotropic conversion of energy at the surface. The prominent 17-day, surface-trapped signal dominated by meridional velocity seen in this CEOF mode is similar to previous analyses of observed velocity at $0^{\circ}, 140^{\circ} \mathrm{W}$
(Halpern et al. 1988; Bryden and Brady 1989; Qiao and Weisberg 1995; McPhaden 1996).

The subsurface temperature variability along $2^{\circ} \mathrm{S}$ (section 3 ) is also dominated by 17 -day variability similar to the velocity variability along the equator. The latitudinal structure of 17-day subsurface temperature along $140^{\circ} \mathrm{W}$ and its relation to equatorial velocity variability will be examined here.

Like the first CEOF of velocity, the amplitude time series for the second CEOF of temperature also has annual modulations consistent with the observed TIW season and a phase representative of a periodic signal (Fig. 7). This annual modulation is presumably from 


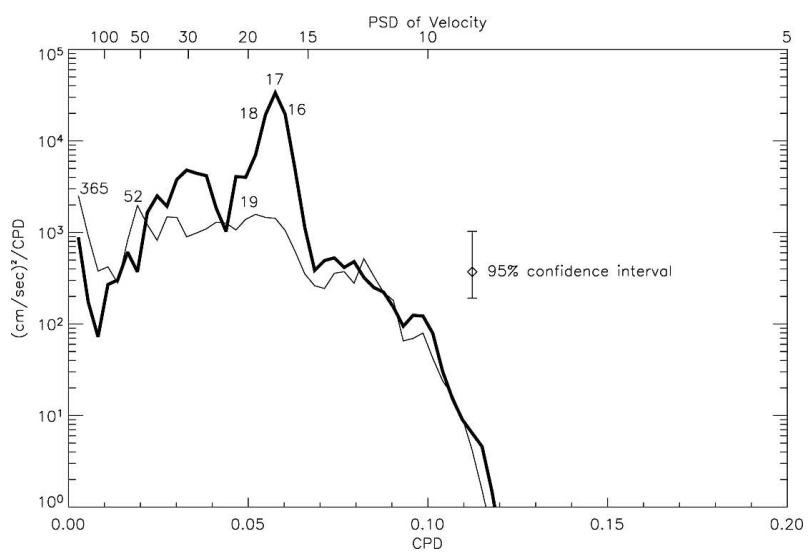

FIG. 12. Power spectral densities following Fig. 8 but for the temperature time series in Fig. 11.

annual variation in the mean current system (Johnson and Proehl 2004). As discussed previously, the period is determined from the PSD of the real part of the CEOF time series (Fig. 7, bottom panel). The second CEOF of temperature is narrow banded with a distinct period of $17 \pm 1$ days, where the frequency resolution is based on the 1-yr record length (Fig. 8).

The 17-day variability in subsurface temperature has a spatial structure (Fig. 14, top panels), which to our knowledge has not been previously observed in subsurface temperature or SSH but has been modeled (as mentioned in the introduction). This mode has maxima at $2^{\circ} \mathrm{N}$ and $2^{\circ} \mathrm{S}$, which are out of phase and larger south of the equator. It explains most of the variance in the thermocline at $2^{\circ} \mathrm{S}$ and $18 \%$ of the total variance. The 17-day period of this mode is the same as the period of the first velocity $\mathrm{CEOF}$ at the equator. Changes in the amplitude of the CEOF time series (Figs. 11 and 7, top panels) are accompanied by changes in the phase (Figs. 11 and 7, middle panels), making it necessary to compute the correlation between the two CEOFs from the real parts of the two CEOF time series (Figs. 11 and 7, bottom panels). The lagged cross correlation of the time series of the first CEOF of velocity (Fig. 11, bottom panel) and the second CEOF of temperature (Fig. 7 , bottom panel) shows that the velocity time series leads temperature time series by 4.25 days (Fig. 15). When the spatial phases (shown in Figs. 13 and 14) are considered, the lag is equivalent to meridional velocity on the equator at the surface, leading temperature at $2^{\circ} \mathrm{S}$ by approximately $90^{\circ}$. These combined characteristics of the first CEOF of velocity and the second CEOF of temperature make up the 17-day TIW observed from the TAO moorings at $140^{\circ} \mathrm{W}$.

The period, wavenumber, and surface-trapped Reynolds stress of the 17-day variability are similar to an unstable solution of the linearized models in McCreary and Yu (1992) and Proehl (1996). Additionally, the cross-equatorial structure of the subsurface temperature, deep vertical structure, and phase relationship between velocity and temperature resemble an equatorially trapped Yanai wave, as predicted by Cox (1980), McCreary and Yu (1992), and Masina et al. (1999a). For these reasons the structure of the Yanai wave in the presence of a realistically sheared mean flow is examined in section $5 \mathrm{~b}$ and compared with these observations.

\section{Kinematics}

The structures of the 33- and 17-day TIWs are compared with results from a linearized two-mode model described in Lyman et al. (2005). In this model, the equations of motion are first linearized about a mean current obtained from the Parallel Ocean Climate Model (POCM) and then the state variables are projected onto the set of vertical baroclinic eigenfunctions. The resulting equations can then be rewritten and solved as an eigenvalue problem by assuming a zonal and temporal structure of $e^{i(k x-\omega t)}$.

\section{a. Unstable Rossby wave}

The structure of the first temperature CEOF closely resembles solutions from Lyman et al. (2005). The most unstable solution from Lyman et al. is identified as an unstable first vertical mode $(n=1)$ and first meridional mode $(m=1)$ Rossby wave with maxima at $5^{\circ} \mathrm{N}$ and $2^{\circ} \mathrm{S}$. Unlike Lyman et al., here the solutions to the model are presented in terms of temperature and not pressure, making a direct comparison with observed CEOFs possible. As in the case of the observed first CEOF of temperature (Fig. 9, top panels), the unstable Rossby wave has in-phase maxima north and south of the equator that are larger in the north with a period of 31 days (Fig. 9, bottom panels) and almost no meridional velocity on the equator. Also, the $1384-\mathrm{km}$ wavelength of the modeled unstable Rossby wave lies within the range of wavelengths estimated from observation in section 3. The maximum amplitudes of the observed first CEOF are slightly deeper and larger in the south than the modeled unstable Rossby wave.

The striking similarity between the observed first CEOF of temperature and the modeled unstable Rossby wave suggests that this wave is a useful description of the 33-day TIW. The model solution has only a small velocity signal on the equator, providing a reasonable explanation for why the observations of velocity on the equator do not contain 33-day variability. The unstable 33-day Rossby wave is generated primarily by barotropic instability, gaining its energy from the 

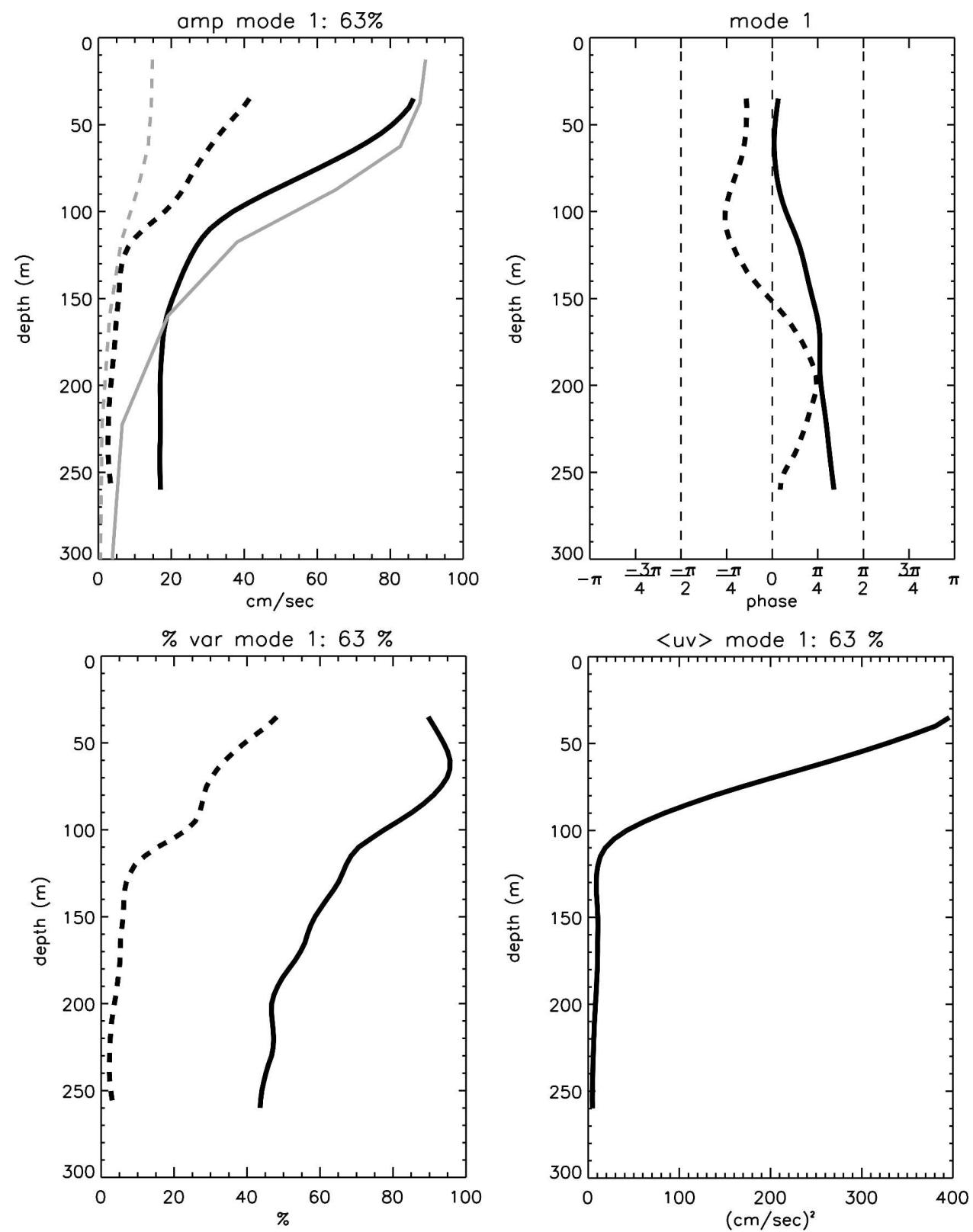

FIG. 13. First velocity CEOF (top left) spatial amplitude, (top right) phase, (bottom left) percent variance explained for meridional (thick solid lines) and zonal (thick dashed lines) velocities, and (bottom right) Reynolds stress. Meridional (thinner gray line in top-left panel) and zonal (thinner gray dashed line in top panel) velocity amplitude of the Yanai wave at the equator from the two-mode projection model scaled to the same order of magnitude as for the CEOF amplitude.

shear between the SECN and the NECC (Lyman et al. 2005).

\section{b. The Yanai wave in a mean zonal current}

The 17-day fluctuations in meridional velocity at $140^{\circ} \mathrm{W}$, presumably produced from surface-trapped instability, are similar to a classical Yanai wave. How- ever, the observed 17-day TIW described herein has a meridional asymmetrical amplitude structure in temperature (Fig. 14, top panels) that is inconsistent with the symmetrical amplitude structure of a Yanai wave in a resting ocean (McPhaden and Knox 1979).

Using the two-mode model and zonal currents from Lyman et al. (2005), the structure of a 17-day Yanai wave in the presence of a mean zonal current is com- 
a) 2nd CEOF \% var, $18 \%$


d) Model Yanai amplitude $\left({ }^{\circ} \mathrm{C}\right)$

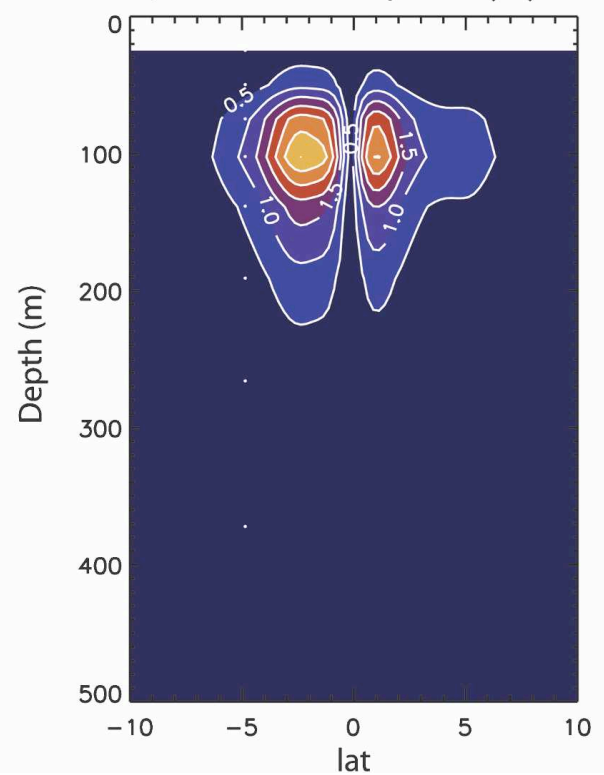

c) 2nd CEOF Phase in Degrees

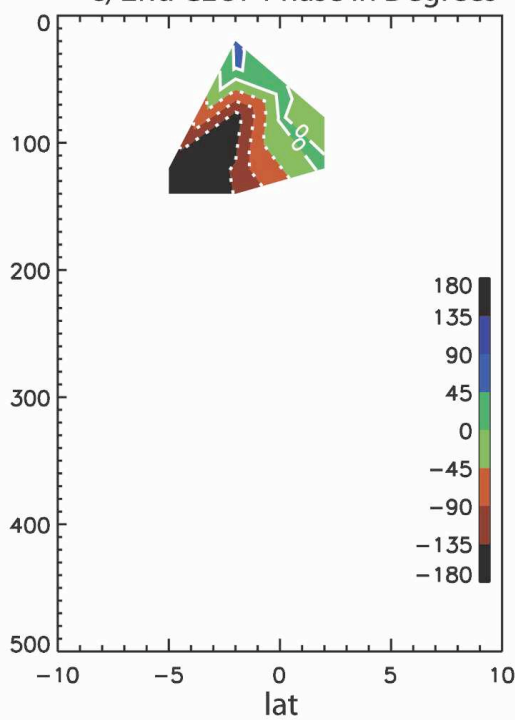

e) Model Yanai Phase in Degrees

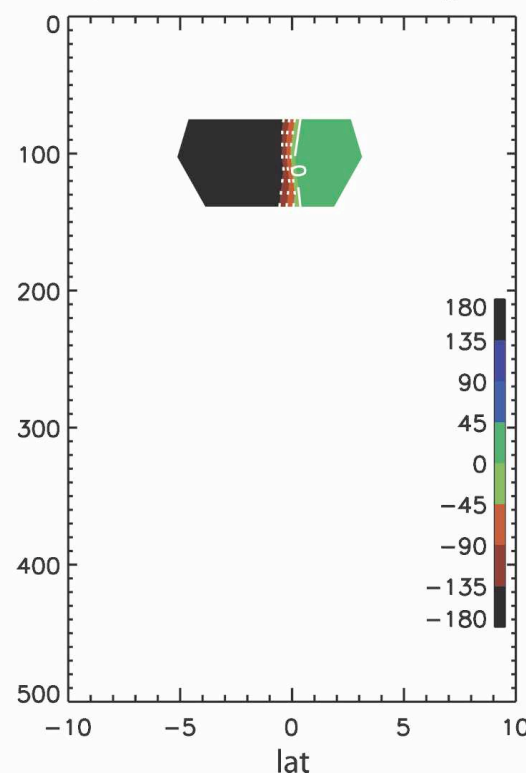

FIG. 14. As in Fig. 9 but for the (a)-(c) second CEOF spatial mode of temperature, and (d), (e) the temperature solution of the $n=1$ Yanai wave computed using the Lyman et al. (2005) model with mean zonal currents. Here the model solution is stable and has a 17-day period and a 1320-km zonal wavelength. Model meridional and zonal velocities are shown in Fig. 16. To match the phase in both (c) and (e), the phase in (c) has been shifted by $-144^{\circ}$.

puted. Because the period of the 17-day TIW is known with a high degree of accuracy, it is used rather than the wavelength to pick the solution to the eigenvalue problem. For the Lyman et al. mean current, a Yanai wave with a 17-day period corresponds to a wavelength of $1320 \mathrm{~km}$, near the rough estimate from section 3. It should be noted that the cross-equatorial structure of the solutions are not very sensitive to changes in wavelength of $100 \mathrm{~km}$. As in McPhaden and Knox (1979), the mean zonal currents decrease the period of the stable $1320-\mathrm{km}$ Yanai wave from 20 to 17 days and shift the maxima in the amplitude of perturbation zonal velocity toward the equator (Fig. 16). Additionally, there are significant changes to the perturbation temperature field resulting in larger amplitudes south of the equator (Fig. 14, bottom panels).

The latitudinal structure of temperature and velocity of the observed 17-day TIW is similar to the 17-day 


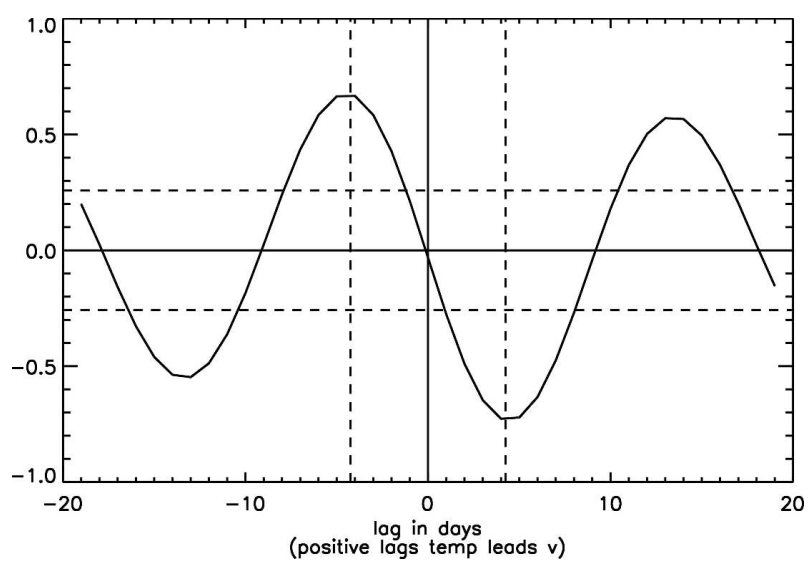

FIG. 15. Lagged cross correlation between real parts of the first CEOF time series for velocity and the second CEOF time series for temperature. For positive lags, temperature leads velocity. Dashed vertical lines show \pm 4.25 days and dashed horizontal lines show $95 \%$ confidence level.

Yanai wave from the two-mode mean current model. Like the modeled Yanai wave, the observed second temperature CEOF has out-of-phase maxima at $2^{\circ} \mathrm{N}$ and $2^{\circ} \mathrm{S}$ that are larger in the south (Fig. 14). Although the degree of asymmetry across the equator is larger in the observations, most of the characteristics of the first velocity CEOF are similar to those of the Yanai wave at the equator; it is dominated by meridional velocity, surface intensified (Fig. 13), and leads temperature at $2^{\circ} \mathrm{S}$ by $90^{\circ}$. These results show that the latitudinal and vertical structure in temperature, period, vertical structure of meridional velocity at the equator, and phase relationship between temperature and meridional velocity for the 17-day TIW are consistent with a Yanai wave in the presence of mean background currents for the central Pacific.

The Reynolds stresses of the observed first velocity CEOF (Fig. 13) are surface trapped, like the modeled 21-day unstable solution from McCreary and $\mathrm{Yu}$ (1992). There is also variability below the thermocline, which is partly explained by the first-mode CEOF of velocity but does not have an associated Reynolds stress (Figs. 5 and 13). Similarly, south of the equator the observed second CEOF of temperature explains a significant amount of the variability below the lower thermocline (Fig. 14, top panel). This agreement between models and observations suggests that these CEOFs are a combination of a surface-trapped instability and a propagating Yanai wave, as proposed by Halpern et al. (1988).

Insight could be gained if, as in the case of the 33-day TIW (Lyman et al. 2005), the 17-day TIW could be described as a resonance of a few equatorially trapped modes. We attempted this by running the linearized model with five vertical modes and by increasing the shear of the mean equatorial currents. However, within reasonable bounds, the solutions to the linearized model were not found to be unstable in the frequencywavenumber range of the 17-day TIW. A possible reason for this is that the 17-day instability is not simply describable as a resonance of a few modes. The surfacetrapped nature of this instability likely takes many more vertical modes to resolve and is probably better described as a combination of a surface-trapped instability and a propagating wave than as a resonance.

\section{Summary and discussion}

TIWs on the equator are consistently observed to have periods around 17 days, while near $5^{\circ} \mathrm{N}$ their period is estimated to be near 33 days. While discussions of both the 17- and 33-day TIWs are prominent in the modeling literature, observation analyses of their crossequatorial structure have been previously, to the best of our knowledge, limited to indirect diagnosis from analysis of energetics or phase speed of an individual eddy, making it difficult to confirm observationally the relationship between velocity on the equator and temperature off the equator. Observations of 17-day variability in subsurface temperature at $2^{\circ} \mathrm{S}$ presented here are shown to be associated with 17 -day velocity variability at the equator and distinct from the dominant 33-day signals previously observed in SSH and subsurface temperature near $5^{\circ} \mathrm{N}$.

Structure of the temperature and velocity data from the TAO moorings along $140^{\circ} \mathrm{W}$ are studied to separate 17-day from 33-day subsurface temperature variability. The spatial and temporal structures of these two physical modes of variability explain the latitudinal differences in TIW period. They are conveniently described from this dataset by the first two temperature CEOFs and the first velocity CEOF.

The 17-day TIW is consistent with a surface-trapped instability/Yanai wave. Its temperature signature has maxima at $2^{\circ} \mathrm{N}$ and $2^{\circ} \mathrm{S}$ that are out of phase and larger in the south (Fig. 14), while the velocity on the equator is dominated by meridional velocity, is stronger at the surface (Fig. 13), and leads temperature at $2^{\circ} \mathrm{S}$ by $90^{\circ}$ (Fig. 15). The structure in both velocity and temperature penetrates below the thermocline. While the 17day TIW is by far the dominant TIW on the equator and at $2^{\circ} \mathrm{S}$ during this time period, its dominance is limited to a region near $140^{\circ} \mathrm{W}$. Large Reynolds stresses, associated with the velocity CEOF at the surface, indicate the presence of instability at the surface, which likely occurs from the EUC-SECN shear (Hansen and Paul 1984; Luther and Johnson 1990; Qiao 

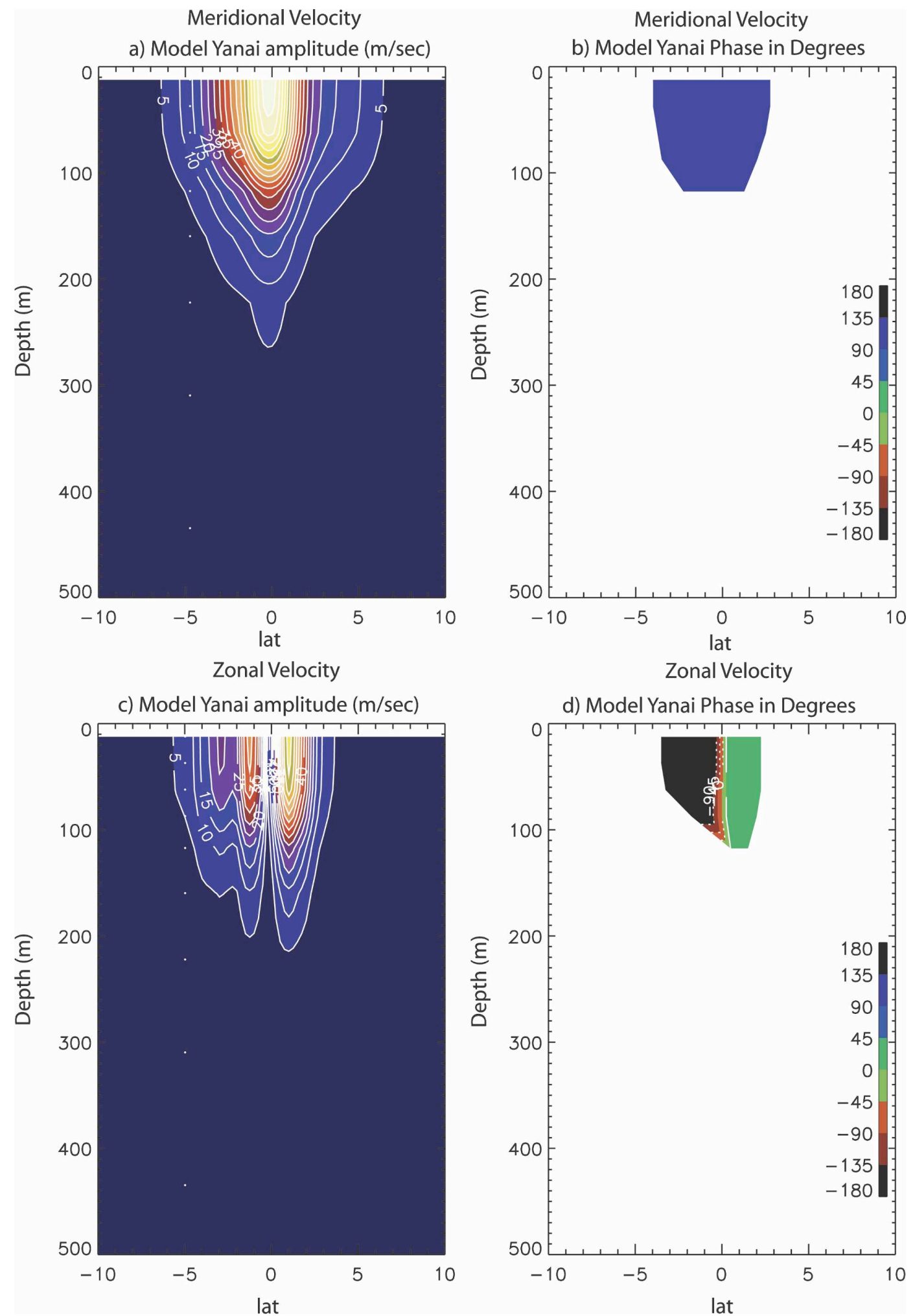

FIG. 16. Depth-latitude plots of (left) amplitude and (right) phase of the $n=1$ Yanai wave with a 17-day period and a 1320-km wavelength computed using the Lyman et al. (2005) mean zonal currents: (a), (b) zonal and (c), (d) meridional velocity $\left(\mathrm{cm} \mathrm{s}^{-1}\right)$. The amplitude of the model has been scaled to be the same order of magnitude as velocity on the equator. Temperature is shown in bottom panels of Fig. 14. 
and Weisberg 1998; Donohue and Wimbush 1998; Masina et al. 1999b) and/or frontal instability in the temperature front associated with the EUC (McCreary and $\mathrm{Yu}$ 1992). The structure of the Yanai wave in the presence of a mean current was computed and shown to have cross-equatorial structure, period, and phase relationship between velocity and temperature (Figs. 16 and 14) similar to the observations.

The 33-day TIW is broad banded in frequency and closely resembles the unstable Rossby wave modeled in Lyman et al. (2005). Its maximum amplitude occurs in temperature at $5^{\circ} \mathrm{N}$ and is in phase across the equator. Along $5^{\circ} \mathrm{N}$ the 33 -day TIW is dominant from $180^{\circ}$ to $110^{\circ} \mathrm{W}$ and is not associated with a meridional velocity signal on the equator. Previous modeling (Philander 1978; Cox 1980; Donohue and Wimbush 1998; Lyman et al. 2005) and observational studies (Luther and Johnson 1990; Baturin and Niiler 1997; Kennan 1997) suggest that the NECC-SECN shear appears to be the most likely energy source for the 33-day TIW. However, baroclinic energy conversion might also provide a significant source of energy for this wave (Cox 1980; Luther and Johnson 1990; Donohue and Wimbush 1998; Masina et al. 1999b; Lyman et al. 2005).

It is possible to separate the 17-day from the 33-day subsurface temperature variability because of the unique characteristics of the data used. First, the TAO array provides daily observations of temperature located near the maxima in amplitudes of both the unstable Rossby wave and the Yanai wave. Second, these moorings are deployed on an ongoing basis and therefore captured a 3-yr record of consecutive La Niña conditions, increasing the frequency resolution of the spectral estimates. While the data are too sparse to resolve zonal structure or energetics of the TIWs, the location, quantity, and quality of the temperature and velocity data are adequate to separate and classify these two waves. Such a separation would be much harder, if not impossible, from satellite measurements of SSH. The current relevant satellite altimeters, Ocean Topography Experiment (TOPEX)/Poseidon, and Jason have repeat periods of approximately 10 days, which are barely adequate to resolve the observed 17-day period of the stable Yanai wave. Additionally, the subsurface temperature variability at $2^{\circ} \mathrm{S}$ and $2^{\circ} \mathrm{N}$ has a small SSH signature relative to the $\mathrm{SSH}$ signal associated with the TIW signal at $5^{\circ} \mathrm{N}$. This difference arises because of large changes in the Coriolis parameter and smaller variability in subsurface temperature at lower latitudes.

This study suggests that caution should be used when estimating the period of TIWs from cusps in the SST front just north of the equator. These cusps occur where the 17- and 33-day TIWs explain equal amounts of the total variance in the thermocline. Hence, the cusps in SST reflect a combination of both physical processes rather than one coherent signal.

Even though linearized models were able to reproduce the observations presented in this paper, TIWs are thought to be highly nonlinear (Kennan and Flament 2000). The periods observed here are 17 and 33 days, which are near-multiples of each other, suggesting a possible nonlinear interaction between the Yanai wave and the unstable Rossby wave. Additionally, possible interaction between these two waves is evident from their similar annual modulations and their estimated zonal wavelengths, which are nearly identical.

Acknowledgments. John M. Lyman was a National Research Council fellow during this research. Additional support was provided by the NOAA Office of Ocean and Atmospheric Research and the NOAA Office of Global Programs. Helpful comments were provided by Dennis W. Moore, Michael J. McPhaden, Eric S. Johnson, and two anonymous reviewers.

\section{REFERENCES}

Baturin, N. G., and P. P. Niiler, 1997: Effects of instability waves in the mixed layer of the equatorial Pacific. J. Geophys. Res., 102, 21 771-21 793.

Bryden, H. L., and E. C. Brady, 1989: Eddy momentum and heat fluxes and their effects on the circulation of the equatorial Pacific Ocean. J. Mar. Res., 47, 55-79.

Chelton, D. B., F. J. Wentz, C. L. Gentemann, R. A. deSzoeke, and M. G. Schlax, 2000: Satellite microwave SST observation of transequatorail Tropical Instability Waves. Geophys. Res. Lett., 27, 1239-1242.

_, M. G. Schlax, S. K. Esbensen, N. Thum, M. H. Freilich, F. J. Wents, C. L. Gentemann, and M. J. McPhaden, 2001: Observations of coupling between surface wind stress and sea surface temperature in the eastern tropical Pacific. J. Climate, 14, 1479-1498.

Contreras, R. F., 2002: Long-term observation of Tropical Instability Waves. J. Phys. Oceanogr., 32, 2715-2723.

Cox, M. D., 1980: Generation and propagation of 30-day waves in a numerical model of the Pacific. J. Phys. Oceanogr., 10, 1168-1186.

Davis, R. E., 1976: Predictability of sea surface temperature and sea level pressure anomalies over the North Pacific Ocean. $J$. Phys. Oceanogr., 6, 249-266.

Donohue, K. A., and M. Wimbush, 1998: Model results of flow instabilities in the tropical Pacific Ocean. J. Geophys. Res., 103, 21 401-21 412.

Emery, W. J., and R. E. Thomson, 2001: Data Analysis Methods in Physical Oceanography. 2d ed. Elsevier, 638 pp.

Eriksen, C. C., and J. G. Richman, 1988: An estimate of equatorial wave energy flux at 9- to 90-day periods in the central Pacific. J. Geophys. Res., 93, 15 455-15 466.

Flament, P. J., S. C. Kennan, R. A. Knox, P. P. Niiler, and R. L. Bernstein, 1996: The three-dimensional structure of an upper ocean vortex in the tropical Pacific Ocean. Nature, 383, 610 613. 
Halpern, D., R. A. Knox, and D. S. Luther, 1988: Observations of 20-day meridional current oscillations in the upper ocean along the Pacific equator. J. Phys. Oceanogr., 18, 1514-1534.

Hansen, D. V., and C. A. Paul, 1984: Genesis and effects of long waves in the equatorial Pacific. J. Geophys. Res., 89, $10431-$ 10440.

Hashizume, H., S.-P. Xie, W. T. Liu, and K. Takeuchi, 2001: Local and remote atmospheric response to tropical instability waves: A global view from space. J. Geophys. Res., 106, $10173-10185$.

Johnson, E. S., and J. A. Proehl, 2004: Tropical instability wave variability in the Pacific and its relation to large-scale currents. J. Phys. Oceanogr., 34, 2121-2147.

Kennan, S. C., 1997: Observations of a tropical instability vortex. Ph.D. thesis, University of Hawaii at Manoa, 190 pp.

- , and P. J. Flament, 2000: Observations of a tropical instability vortex. J. Phys. Oceanogr., 30, 2277-2301.

Legeckis, R., 1977: Long waves in the eastern equatorial Pacific Ocean: A view from a geostationary satellite. Science, 197, 1179-1181.

_ 1986: Long waves in the equatorial Pacific and Atlantic Oceans during 1983. Ocean-Air Interactions, 1, 1-10.

— - E. Pichel, and G. Nesterczuk, 1983: Equatorial long waves in geostationary satellite observation and in a multichannel sea surface temperature analysis. Bull. Amer. Meteor. Soc., 64, 133-139.

Luther, D. S., and E. S. Johnson, 1990: Eddy energetics in the upper equatorial Pacific during Hawaii-to-Tahiti Shuttle Experiment. J. Phys. Oceanogr., 20, 913-944.

Lyman, J. M., D. B. Chelton, R. A. deSzoeke, and R. M. Samelson, 2005: Tropical instability waves as a resonance between equatorial Rossby waves. J. Phys. Oceanogr., 35, 232-254.

Malardé, J. P., P. D. Mey, C. Périgaud, and J. F. Minster, 1987: Observations of long equatorial waves in the Pacific Ocean by Seasat altimetry. J. Phys. Oceanogr., 17, 2273-2279.

Masina, S., G. Philander, and A. Bush, 1999a: An analysis of tropical instability waves in a numerical model of the Pacific Ocean. Part I: Spatial variability. J. Geophys. Res., 104, 29 613-29 636.

$\ldots, \ldots$, and $—, 1999 \mathrm{~b}$ : An analysis of tropical instability waves in a numerical model of the Pacific Ocean. Part II: Generation and energetics. J. Geophys. Res., 104, $29637-$ 29662.
McCreary, J. P., and Z. Yu, 1992: Equatorial dynamics in a 2.5layer model. Progress in Oceanography, Vol. 29, Pergamon, $61-132$

McPhaden, M. J., 1996: Monthly period oscillations in the Pacific North Equatorial Countercurrent. J. Geophys. Res., 101, 6337-6359.

- and R. A. Knox, 1979: Equatorial Kelvin and inertio-gravity waves in zonal shear flow. J. Phys. Oceanogr., 9, 263-277.

_, and Coauthors, 1998: The Tropical Ocean-Global Atmosphere observing system: A decade of progress. J. Geophys. Res., 103, 14 169-14 240.

Miller, L., D. R. Watts, and M. Wimbush, 1985: Oscillations of dynamic topography in the eastern equatorial Pacific. J. Phys. Oceanogr., 15, 1759-1770.

Musman, S., 1989: Sea height wave form in equatorial waves and its interpretation. J. Geophys. Res., 94, 3303-3309.

Périgaud, C., 1990: Sea level oscillations observed with Geosat along the two shear fronts of the Pacific North Equatorial Countercurrent. J. Geophys. Res., 95, 7239-7248.

Philander, S. G. H., 1978: Instabilities of zonal equatorial currents, 2. J. Geophys. Res., 83, 3679-3682.

Proehl, J. A., 1996: Linear stability of equatorial zonal flows. $J$. Phys. Oceanogr., 26, 601-621.

Pullen, P. E., R. L. Bernstein, and D. Halpern, 1987: Equatorial long-wave characteristics determined from satellite sea surface temperature and in situ data. J. Geophys. Res., 92, 742748

Qiao, L., and R. H. Weisberg, 1995: Tropical instability wave kinematics: Observations from the Tropical Instability Wave Experiment. J. Geophys. Res., 100, 8677-8693.

— and - 1998: Tropical instability wave energetics: Observations from the Tropical Instability Wave Experiment. $J$. Phys. Oceanogr., 28, 345-360.

Seidel, H. R., and B. S. Giese, 1999: Equatorial currents in the Pacific Ocean 1992-1997. J. Geophys. Res., 104, 7849-7863.

Strutton, P. G., J. P. Ryan, and F. P. Chavez, 2001: Enhanced chlorophyll associated with tropical instability waves in the equatorial Pacific. Geophys. Res. Lett., 28, 2005-2008.

Xie, S.-P., M. Ishiwatari, H. Hashizume, and K. Takeuchi, 1998: Coupled ocean-atmospheric waves on the equatorial front. Geophys. Res. Lett., 25, 3863-3866. 